\title{
Social care graduates' judgements of their readiness and preparedness for practice
}

\author{
Fiona McSweeney \\ Technological University Dublin, fiona.mcsweeney@tudublin.ie \\ David Williams \\ Technological University Dublin, david.williams@tudublin.ie
}

Follow this and additional works at: https://arrow.tudublin.ie/aaschsslarts

Part of the Educational Sociology Commons, Higher Education Commons, Other Education Commons, and the Social Work Commons

\section{Recommended Citation}

Fiona McSweeney \& Dave Williams (2019) Social care graduates' judgements of their readiness and preparedness for practice, Social Work Education, 38:3, 359-376, DOI: 10.1080/02615479.2018.1521792

This Article is brought to you for free and open access by the Social Sciences at ARROW@TU Dublin. It has been accepted for inclusion in Articles by an authorized administrator of ARROW@TU Dublin. For more information, please contact arrow.admin@tudublin.ie, aisling.coyne@tudublin.ie,gerard.connolly@tudublin.ie.

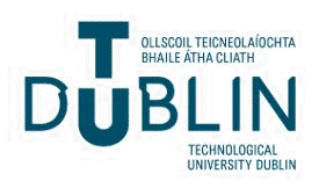




\section{Social care graduates' judgements of their readiness and preparedness for practice}

\section{Fiona McSweeney \& Dave Williams}

To cite this article: Fiona McSweeney \& Dave Williams (2019) Social care graduates' judgements of their readiness and preparedness for practice, Social Work Education, 38:3, 359-376, DOI: 10.1080/02615479.2018.1521792

To link to this article: https://doi.org/10.1080/02615479.2018.1521792

\section{Published online: 23 Sep 2018.}

Submit your article to this journal ๔

山ll Article views: 383

Q View related articles $\asymp$

View Crossmark data

4 Citing articles: 1 View citing articles 


\title{
Social care graduates' judgements of their readiness and preparedness for practice
}

\author{
Fiona McSweeney (iD) and Dave Williams \\ School of Languages, Law and Social Science, Dublin Institute of Technology, Dublin, Ireland
}

\begin{abstract}
While research has been conducted on social work graduates' views of their readiness and preparedness for practice, the views of social care workers have not been specifically researched. This paper reports on the views of social care graduates in Ireland of how ready they are to join the workforce and how their educational programme has prepared them. Two semi-structured interviews were conducted with the same participants. The first was at the end of their final year in college and the second between 9 and 12 months later when they were in employment. Findings indicate that participants, while apprehensive, felt ready for the workforce. Although awareness of the difference between placement and work was apparent, placement was seen as essential preparation. Differences were apparent in judgements of academic modules, suggesting that views on the usefulness of different knowledge types are subjective. Common however was an increasing focus on the usefulness of practical knowledge after time in employment suggesting that, as found in research involving experienced practitioners, the theoretical underpinnings of practice are not emphasised in the workplace. Suggestions are made for educators to maintain an approach to practice that is informed by a body of knowledge beyond specific workplace practices.,
\end{abstract}

\section{ARTICLE HISTORY}

Received 6 December 2017

Accepted 5 September 2018

\section{KEYWORDS}

Social care graduates; readiness; preparedness; practice; education

\section{Aim and rationale}

This paper focuses on social care students' views of readiness and preparedness to practice at the end of their educational programme and when they were in employment. It is part of a broader study about anticipations and experiences of the transition to practice in Ireland, a group that have not been researched. Accepting that 'preparedness is a contested concept' (Tham \& Lynch, 2014, p. 706) and self-rated preparedness could be a 'measure of confidence rather than actual ability' (Galvani \& Forrester, 2011, p. 434), the aim was to explore the participants' perspectives of their readiness and preparedness rather than measuring them against pre-determined factors. In this research, readiness is viewed as the participants' perceptions of whether they feel capable of practising as social care workers and preparedness as the participants' views of how aspects of their educational programme have facilitated their readiness. Thus, as discussed below, readiness focuses on factors that are not necessarily provided by the educational programme while preparedness does.

CONTACT Fiona McSweeney fiona.mcsweeney@dit.ie; Dave Williams david.williams@dit.ie D Dublin Institute of Technology RD105 Rathdown House, Grangegorman, Dublin 7, Ireland 
Due to the lack of literature in relation to social care and commonalities between it and social work, the majority of the literature reviewed refers to social work. While in the United Kingdom social care work and social work are not clearly distinguished, in Ireland the two professions and their education programmes have evolved separately (see McSweeney, 2017). However there are commonalities. Both recognise the effect of marginalisation and hence the need for supporting and empowering clients. The primary difference is that social care emphasises working in the life spaces of clients to meet their needs while social workers have a case-management role and statutory responsibility (Irish Association of Social Workers, 2016; Social Care Ireland, 2016). The knowledge base of each is similar as is the breadth of areas in which they work.

As social work has expanded into a range of settings (Healy \& Meagher, 2007; Jack \& Donnellan, 2010) so too has social care work. From its roots in residential child care, practitioners now work with a range of service users and in a variety of statutory and private services both residential and community based (Byrne, 2016; McSweeney, Smith, \& Williams, 2016).

Social care and social work are underpinned by a variety of knowledge types (McDonald, 2007; Trevithick, 2008; Van Bommel, Boshuizen, \& Kwakman, 2012). This includes theoretical knowledge about the role and purpose of the work as well as that borrowed from disciplines such as psychology and sociology, factual knowledge about legislation and policy, practical skills and self-regulative knowledge (Frost, Höjer, \& Campanini, 2013; Trevithick, 2008; Van Bommel, Boshuizen, \& Kwakman, 2012). However, as will be discussed below, stakeholders vary in their judgements of the relevance of different types of knowledge.

Social care education programmes in Ireland are at Level $6^{1}$ in the European Qualifications Framework. Programmes include academic modules to provide students with theoretical and factual knowledge and a minimum of 800 hours on field placement to develop practice skills, increase self-awareness and integrate theory with practice (Irish Association of Social Care Educators, 2009).

\section{Readiness to practice}

Several studies explored skills that social work students and graduates said they had and needed to have to be ready to practice. Areas where participants considered themselves not competent are dealing with hostility and aggression from clients and managing conflict (Sharpe, Moriarty, Stevens, Manthorpe, \& Hussein, 2011; Wilson, 2013), dealing with clients in severe crisis (Tham \& Lynch, 2014) and risk assessment (Pithouse \& Scourfield, 2002; Sharpe et al., 2011). Application of social work values was found to be the area where participants considered themselves most competent by Pithouse and Scourfield (2002) and Wilson (2013). Jack and Donnellan's (2010) newly qualified social workers (NQSWs) said they were particularly competent in relationship and teamwork skills when they graduated. However they realised after time in practice that decisions they had to make resulted in clients disliking them, thus testing these beliefs.

Research also suggests social work graduates consider themselves more ready to work with some client groups than others (Galvani \& Forrester, 2011; Wilson, 2013). Redmond, Guerin, and Devitt (2008) found that social work students' views of the level of expertise required and their readiness for different areas of practice were most 
strongly influenced by their own and their classmates' placement experiences as well as interaction with qualified practitioners. Likewise Wilson (2013) and Tham and Lynch (2014) report students' views of readiness for different areas of social work was influenced by experience in that area either from placement or previous work. NQSWs who had no previous experience of an area felt they did not have sufficient skills to interact effectively with clients and had to learn about the work as they worked (Tham \& Lynch, 2017).

Regarding employers' views, Yu, Moulding, Buchanan, and Hand (2016) report expectations that new social work graduates be functionally competent, particularly in skills needed for direct practice with clients. Knowledge of social work values and principles were seen as most important for beginning practitioners. Managers report NQSWs ability to conduct assessments and risk assessment inadequate (Pithouse \& Scourfield, 2002; Sharpe et al., 2011). Other research in relation to social work reports that practitioners emphasise the need for critical thinking, conceptualisation of issues, self-reflection, emotional awareness and regulation, as opposed to specific skills (Healy \& Meagher, 2007; Sussman, Bailey, Byford Richardson, \& Granner, 2014). Representatives of higher education institutions teaching social work in the United Kingdom agree, arguing that what is necessary for the work is being 'critical and reflective practitioners'. They object to what they see as functional readiness wanted by employers (Wilson, 2014; Sharpe et al., 2011, p. 92).

In summary, apart from dealing with aggression, hostility and conflict and conducting risk assessments graduates view themselves as relatively competent in direct practice skills. Readiness for practice is not equal across all areas of social work and is influenced by prior experience and knowledge. Employers concur with graduates in relation to conducting assessments. Both functional competence in direct practice skills and meta-cognitive capabilities are differentially mentioned as valued for practice by experienced workers.

\section{Preparedness to practice}

New graduates are reported to feel under pressure to have full knowledge of different social work practice areas (Sharpe et al., 2011). British research reports that between half and three quarters of NQSWs consider that their degree prepares them for practice in at least some areas (Bates et al., 2010; Grant, Sheridan, \& Webb, 2017; Sharpe et al., 2011). Preparedness in areas such as engaging with clients and carers, listening skills, reflective practice, inter-professional and interagency working and empowering clients (Sharpe et al., 2011), report writing and conducting assessments (Grant et al., 2017) are mentioned. Other studies report that covering specific material in relation to social work with particular client groups during education influences graduates' feelings of preparedness (Galvani \& Forrester, 2011; Tham \& Lynch, 2017).

With regard to employers' views, most managers questioned by Bates et al. (2010) see NQSWs as adequately prepared and indeed judge them more prepared in some areas, than the NQSWs do themselves. On the other hand, Newberry (2014, p. 42) points out that metaphors such as 'hitting the ground running' are common in discourses about NQSWs in both Britain and Canada, with failure to do so associated with criticism of educational programmes for inadequate preparation. While managers acknowledged that it was not possible to prepare students fully for the realities of 
practice and that much development could only come through experience', they still criticised the social work degree for not teaching students to 'apply their learning in the context they would be faced with in practice' (Sharpe et al., 2011, p. 92).

\section{The value of theory}

Variation is found within and between studies in relation to social work students' and graduates' views of the value of theoretical knowledge and who is responsible for helping with the integration of theory with practice (Frost et al., 2013). Only $40 \%$ of the graduates surveyed by Sharpe et al. (2011) said theories learned on their programme were useful in their work. Preferred are modules that are 'concrete and practical', as theoretical material is seen as difficult to understand and apply (Simpson, Mathews, Croft, McKinna, \& Lee, 2010; Tham \& Lynch, 2014, p. 709). Also favoured is 'reality based' teaching reflecting the 'sharp end' of practice thus helping deal with 'real pressures' (Bradley, 2008, p. 357), delivered by educators who 'made the topic 'real', 'illustrated the value of the learning to direct professional practice' and used their own practice experiences as examples (Simpson et al., 2010, p. 733). Experienced social workers also value the learning that can be achieved through hearing the 'stories' of colleagues' experiences (Beddoe, 2009). Appreciation that time is needed to integrate knowledge through reflection and the relevance of material may not be immediately apparent is found with some graduates (Simpson et al., 2010). Similarly Fook, Ryan, and Hawkins (2000) report that NQSWs have knowledge about facts and concepts but do not use these to reason and make decisions. Van Bommel, Kwakman, and Boshuizen (2012, p. 537) found that final year social work students who can evaluate theory and see it as a system of meaning making use it to analyse cases and are less likely to judge its value solely on whether it can be directly applied in practice.

Practitioners also vary in how they value theory, which could influence graduates' views. Dustin (2006) reports that while care managers in England view social work as being underpinned by theoretical and factual knowledge, they could not name theories and did not directly and consciously apply it. On the other hand, they could articulate factual knowledge. Some considered theory to be dangerous if used too narrowly and others emphasised the need to follow specific policies did not facilitate the use of theory. Irish research with social care practitioners reports resistance to theoretical knowledge, considering it to be "academic" thus positioned in opposition to "practice" and not being directly relevant, used as an excuse rather than an explanation for behaviour (Feeney, 2016; McSweeney, 2017). Irish and Canadian child welfare practitioners refer to 'complicated over-theoretical' material as being a barrier to using it to inform practice (Buckley, Tonmyr, Lewig, \& Jack, 2014, p. 12). Social care practice teachers also vary in whether they see linking theory with practice as their responsibility or that of college lecturers (McSweeney, 2017). Conversely Gordon and Cooper (2010, p. 249) report that social work practitioners in Scotland used a 'diverse range of knowledge' to inform their practice, including theory.

\section{The role of field placement}

Although placement is viewed as essential preparation for social care and social work practice, with both students and employers particularly valuing it when the placement was in the same area of practice as the graduate is working (Baginsky \& Manthorpe, 2016; Bates 
et al., 2010; McSweeney \& Williams, 2018; Wilson, 2013), there are differences between placement and work. NQSWs note that students are protected on placement so do not experience either the busyness or 'ethical dilemmas' that are encountered in practice (Agllias, 2010, p. 357) nor the politics of the workplace (Le Maistre \& Paré, 2004). Wilson (2013, p. 604) argues that placement cannot always provide opportunities to develop a 'full range of skills required to practise confidently and effectively'. Similarly managers and educators in England note the variability between placements regarding the work students could engage in and support provided for their learning (Sharpe et al., 2011).

To summarise, educational programmes in social work are judged to be adequate preparation by the majority of graduates in previous research, but employers' views vary. While the work is underpinned by theoretical as well as factual and practical knowledge, social work and social care work graduates and practitioners have mixed opinions regarding the value of theory. Although the field placement is seen as essential preparation differences between it and the workplace impact on its contribution to preparing graduates for the workplace.

\section{Challenges in preparation for practice}

Daley (2001) argues that integrating knowledge with practice is not a simple transfer of knowledge but instead requires reconstruction through individual reflection on interactions in professional work. Billett (2013) argues that classroom learning has to be decontextualised and then re-contextualised in the workplace and requires individuals' effortful engagement' (Billett, 2014, p. 8). The use of knowledge in the workplace is also affected by the situational factors within that workplace (Billett, 2001, 2015) as well as the identities, goals and mental models of practitioners (Billett, 2010; Sandars, 2005). As Le Maistre and Paré (2004, p. 45) point out 'school and work are radically different activity systems' with different rules, aims and ways of achieving these. The broad range of employment areas and differential requirements within social care and social work creates further complications for preparing students for practice (Healy \& Meagher, 2007). Bates et al. (2010, p. 155) argue that' professional development should be viewed as "being" rather than just "knowing" so the learning required for professional competency continues after the programme of formal education and requires a learning culture within organisations (Nixon \& Murr, 2006). Students at the end of their programme and NQSWs consider themselves to be novices or advanced beginners, being conscious of their incompetence and inexperience' (Fook et al., 2000; Frost et al., 2013, p. 340). Graduates may also be overly conscious about appearing and being competent in line with employer expectations, discussed above.

Fook et al. (2000) report that NQSWs are concerned about appearing professional and doing their job well rather than reflexivity. Similarly Pösö and Forsman (2013) report that novice child protection social workers in Finland are more concerned about following procedure compared to veteran workers. Le Maistre and Paré $(2004$, p. 48) propose that new practitioners 'faced with the hurly-burly of the workplace' use ways of 'getting through the day' rather than transforming the theories and methods learned into tools of practice. They propose it takes time and the space for reflection to practice in a way that is informed by learning. With regard to residential child care in the United Kingdom, workload, the 
lack of facilitation for reflective practice and little encouragement from management impact negatively on the use of knowledge for and in practice (Forester-Jones \& Hatzidimitriadou, 2006; McPheat \& Butler, 2014; Smith, 2005).

Thus educators face particular challenges in preparing students for practice in the fields of social work and social care, including differences between the college and work environments that inhibit knowledge transfer, the focus of new graduates on appearing competent as well as factors inherent in employing organisations.

In conclusion, existing research indicates that graduates mainly consider themselves as ready and prepared for practice in social care and social work. However conflict is evident between the priorities of educators and employers, which cause particular challenges for educational institutions. The research reported here explored the views of students (pre- and post-graduation) regarding their preparation for social care workplaces thus allowing some comparison of change.

\section{Methodology}

To access the individual experiences and views of participants, an interpretivist approach was used and data were collected using individual semi-structured interviews. The relativist epistemology of interpretivism is acknowledged and that the findings being reported are reflexively contextualised and comprise a truth rather than the truth' (McLeod, 2001, p. 38).

\section{Participants}

From a class of 42 students, 17 volunteered to participate in the research: Four males and 13 females. At the first point of data collection, the mean age of participants was 24.7 years (SD 7.4 years) and ages ranged from 20 to 49 years. At the time of the second interview, three participants had obtained full-time work with social care agencies. The remainder were employed as relief staff, as outreach workers through social care agencies and two were completing internships. Participants were working in a variety of areas such as residential childcare, homeless services, intellectual disability and autism services and domestic violence services. The advantage of using a volunteer sample was that participants were motivated to recount their experiences but the limitation that the views of those who did not volunteer is acknowledged. However the aim of the research is not to generalise but to explore individual experiences, in line with an interpretivist approach.

\section{Ethics}

Ethical approval was obtained from the institution's ethics committee. The students in the class group were given a presentation about the research. They were provided with an information sheet detailing that the aim of the research was to explore their views of their preparedness, readiness, anticipations and experiences of work. They were assured that participation was voluntary and their success in the programme would not be affected. As they knew the researchers, they were given the option of choosing their interviewer. They were asked to spend time considering whether they would like to participate before emailing the person they chose to interview them. Prior to each 
interview, participants were told they had the right not to answer any questions asked and to withdraw from the research during or after data collection. They were also informed that both recordings and transcribed interviews would be securely stored and that all information would be anonymised. This was detailed on the participant consent form signed prior to the first interview. After transcription, participants were sent a copy of the transcript for their comments and opportunity to remove anything they did not want to be used in the analysis. Nobody requested deletions.

\section{Data collection procedure}

The first interview was conducted after all academic work and placement had been completed and the second interview between nine and 12 months later. For the second interview, contact was made with participants via email; 16 of the original 17 participants responded but in two cases interviews were cancelled due to participants' work commitments.

For both interviews, participants were provided with the interview schedule a week beforehand. Most interviews were conducted in the college.

Interviews are seen as being interactive processes in which both the researchers and participants construct individual and collective subjectivities (Rapley, 2001). While Hammersley (Hammersley, 2003, p. 123) argues that interviews 'will often be shaped by concerns about self-presentation or persuasion', the pre-existing knowledge of each other between researchers and participants in this study could be seen to limit this.

\section{Analysis}

Transcripts were read several times and coded in relation to the participants' judgements of their readiness for the workplace in general and in specific areas of practice and influences on this, as well as what aspects of the college programme they found useful in preparing them for work. Thus analysis was deductive. Direct quotes from the participants were assigned to each of the categories individually by the two researchers then jointly revised until consensus was reached to ensure face validity (Guest, MacQueen, \& Namey, 2012). Participants are identified in the findings in the order in which they were interviewed for the first interview (P1, P3 and P15 did not take part in the second interview). The first interview is denoted by I1 and the second by I2.

\section{Findings}

\section{Being ready}

In the first interview, five of the 17 participants stated that they were unequivocally ready for the workplace, all referring to placement learning contributing to their skills and confidence. Participants also spoke about having 'to fly the nest, get out there and do it' (P2/I1) and 'get in there and start working' (P7/I1):

I've gained a lot of skills over the last three years. I've become very confident. I can reflect well. I think I'm good at building relationships with clients. [...] I learned that I can actually stop myself from reacting in those professional situations. (P5/I1) 
I feel a lot more confident now in being able to engage with clients and meet their needs and engage with staff as well on a professional level. [...] I feel less apprehensive now of going into different kinds of work because you have three different types of work behind you. (P12/I1)

The majority of participants expressed mixed views of the prospect of work being 'exciting but terrifying' (P8/I1) or being ready 'in some ways' (P11/I1). They expressed views suggesting conditional readiness in relation to the area of social care where they felt most ready to work. This was based on their own placement experiences, the stories they heard from others and their age:

I think if I went into the area of addiction or homelessness I think I have a good bit of experience behind me that will stand to me. (P1/I1)

With regard to age determining their confidence to work in different areas, this was a very individual judgement and related to views on whether clients would respect them. The quotes below are from two participants of the same age giving their reasons why they were ready and not ready to work in residential services for young people:

I'd definitely like to work with younger people. Just at this stage of my life I think me working with older people, they might not respect you as much. Maybe that is just my view. (P17/I1)

If I was to work in a residential setting this year anyway because I am young. I think if I was to go in there as a care worker they might not have as much respect or might not listen to anything I say to them. (P14/I1)

\section{Developing confidence with experience}

In the second interview, participants spoke of initial challenges about responsibility and skills expected of them as workers but quickly developing confidence in their abilities, except for the level of paperwork required in residential care for young people, which took longer:

My first day, you're sitting with some of the clients and seeing their challenging behaviour going how I will I deal with that, but within three weeks you're doing it, managing it. (P10/ I2)

'Three SENs [significant event notifications] need to be filled out there tonight [name], do you mind getting on to that?' and I am like 'Jesus' and this is the most daunting task ever for me. Like looking up contact books and all 'Who am I going to email and fax about this now?' And I would just be getting into the swing of the paperwork now. (P17/I2)

However some areas of social care were experienced as being more difficult due to the level of challenging behaviour and clients not wanting to engage. Participants spoke of being disheartened working in some homeless services when 'you want to engage with them and access services for whatever issues they may have but they don't want to engage with you' (P12/I2). Working with clients who wanted to use the service as opposed to involuntary clients was seen as more rewarding:

In a way it is kind of like they appreciate it more, you helping them and you know you are making a difference when you are working with them. Whereas you are working with youths in a residential service they are just fing and blinding you all day and they hate being there. 
The disability service they want to come there. [...] They will actually tell you 'Oh yeah, I love coming in here'. So you are know they are getting something out of it. (P14/I2)

\section{Preparation-placement}

The learning achieved and how it was achieved on placement by this group of students is fully discussed elsewhere (McSweeney \& Williams, 2018). In summary, placement prepared students for practice through providing additional learning not covered in college: 'there's certain social care tools that people use in work that you don't learn here' (P4/I1); learning 'to adapt and make the most of opportunities you have [with clients]' (P3/I1); experiencing 'the different fields of social care' (P13/I1); getting 'real experience' (P14/I1); and appreciating the 'complexity of practice' (P8/I1). In particular placement helps with developing your 'own skills' (P12/I1) 'learning about yourself (P15/I1) and you 'start to actually see the theory that you've learned and apply it to different situations (P1/I1).

In the first interview, participants were asked whether they considered the expectations of placements to be progressive throughout the three years. While most did others pointed out that it depended on the setting:

I think definitely because I don't think you could have put me in work with separated children in first year. I had to grow, like you can't put someone from primary school into college. You need to move up the levels before you can reach that phase. So I felt it was a gradual movement. (P7/I1)

[Residential] it was more observing. I wasn't allowed an awful lot of scope. [...] I could identify work that I would like to do, but the scope wasn't there. (P10/I1)

Looking back on the value of placement in the second interview, participants considered the most important contribution the field placement in preparing them for the workplace was the level of responsibility and accountability afforded to them:

Looking back I was given a huge amount of responsibility in third year; I just didn't realise it at the time. And looking back I was very much accountable for my caseloads and all the work I had done, I don't think I realised it at the time. [...] I feel like if I hadn't had that placement I wouldn't be in as good a position as I was going in. (P11/I2)

However differences between being a student on placement and being a staff member were also pointed out suggesting that placement cannot fully prepare one for the workplace. Participants spoke of the contrast between being 'told to get into the office and stay there' when issues arose when they were students compared to being told to 'get out there on the floor and sort that out' (P7/I2) when they were workers. They also noted the busyness of the workplace, the additional responsibilities as workers in relation to recording information, making decisions and challenging clients about behaviours:

I think still even making decisions, I would not pass it on to someone else, but ask somebody because I'm not sure. The kids get so frustrated and I'm like 'Listen lads, I'm not under pressure to make a decision here so hold your horses.' Because they just see me as staff, like I have the answers. (P2/I2) 


\section{Preparation-college modules}

In the first interview when asked what aspects of the modules covered during the programme helped prepare them for practice, six participants said all of them, as well as noting that it took time to realise the relevance of material covered in class:

Like all the modules and genuinely they all do have it. At the time when you're doing them sometimes you kind of think this doesn't have anything to do with it. It sounds really bad but it is only when you take a step back and you look at it from an overall perspective. (P16/I1)

Others $(n=7)$ mentioned modules they considered to have direct practical application:

The challenging behaviour module. Knowing to step back and not be in their face. To watch your posture and tone of voice and all that [...]. (P5/I1)

I thought counselling skills was really good. I used that a lot in my placement working with young people because a lot of them wanted to talk and even the simple skills we were given, our listening skills and things like that. (P13/I1)

Conversely four participants spoke of the benefits of learning to think critically, question and viewed theory as other than a direct guide to action:

I think the big thing is college has led you to question things as well. (P7/I1)

I suppose as much as I complain about it learning to be critical, to be able to step back and go what is really going on. (P3/I1)

\section{Looking back college preparation}

In the second interview, participants were also asked which aspects of the academic modules they found useful in practice. Three participants, as opposed to six in the first interview, referred to how different aspects of the educational programme integrated to 'create a frame of mind' (P4/I2). Most referred to particular material covered in specific modules that were useful in their current role. Different aspects of psychology such as attachment, developmental level, regression, labelling, prejudice and stigma, attribution and emotional self-regulation were mentioned. Five participants referred to the importance of values and principles of practice such as confidentiality, being non-judgemental and focusing on clients' strengths:

Definitely like strengths based perspective, that stayed in my head since I left college. I always try to use that because I think in my area [autism service] a lot of the time everyone looks at things that people can't do. (P16/I2)

Similar to Interview 1, participants discussed the value of modules considered to be 'practical' or had direct application to practice: 'like the challenging behaviour; the practical kind of modules [...] A lot of the theory aspects I haven't really used at all' (P14/I2), that provided tools to use with clients 'the cup with cling film and the water' (P2/I2). Three participants mentioned 'the stories that [lecturers] told us about yourselves working with clients [...] and how you dealt with clients' (P17/I2), 'the stories from somebody who had the experience and how they dealt with things and it either worked or didn't work' (P13/I2). 
Suggesting that space for reflection away from the workplace encourages using theory to understand clients and practice one participant said:

I was thinking about this a few weeks ago because of my role and then I was thinking about it differently today. Because of my role a few weeks ago I was thinking the only thing I'm applying here is the challenging behaviour module. Then today when I was thinking about it I was like ah no it's all principles of professional practice, social theory, child and youth care approach, family law, ecological stuff. Then I was thinking social policy. But the risks side. Everything is a risk assessment. (P9/I2)

While others, when asked about what was useful to practice now from modules covered, said, 'I haven't had to think about this in ages' (P9/I2) and another 'I can't remember. To be honest that is another reason why I want to get out, because I feel like I am losing a lot of what I did in college, bar the actual practices' (P13/I2). Another four participants spoke about the value of the emphasis on reflective practice during their college programme, with one still keeping a reflective diary (P2/I2):

It would have been a big thing really in third year and second year but all of that is kind of reflective pieces. They are quite useful. I mean if you can't self-reflect you are never going to progress. [...] Because if you let a moment pass that is it, it is gone forever. If you kind of actively try and reflect on it and think 'Alright, well how did this go? And how could I have helped?' (P17/I2)

When asked what was needed for practice but not included in the programme, some participants referred to wanting more information relevant to the specific area of practice they were working in such as autism (P16/I2) or faecal smearing (P14/I2). However some participants realised that college could not cover all the material needed due to the breadth of social care work:

In this particular job you need to know the ins and outs of the Community Welfare Service, you need to know the rights of tenants and the difficulties that could happen and community services in particular areas. There is no way you would cover all of that in college. (P11/I2)

With one pointing out that the employer had a responsibility:

I feel once we leave college there's a lot of responsibility passed to the organisation which you choose to work with. I think maybe a lot of the time the organisation doesn't take on that responsibility as much as they should. [...] I can't think of anything in college that should have been there. (P4/I2)

After experience of the workplace, some admitted that they did not realise the importance of material covered when they were in college:

At the time like I was like 'Why are they harping on about this [reflection]?' but when you leave and you actually are working you can really see that is where the best learning is done. (P13/I2)

As a group you look into community services. You don't actually understand how important they are or like you just kind of pluck things out and go that will do. So I just pick three. It doesn't really matter which ones. (P11/I2)

Or take up opportunities when provided, such as 'how to find a job.CV preparation and all that' (P5/I2) and training in therapeutic crisis intervention: 
You offered it [TCI] as well at the discount price. I mean that was completely my own fault. I decided to go off and travel around Europe instead. (P17/I2)

\section{Discussion}

Although they were aware of their inexperience, participants mainly felt that they were ready to progress from college to work at the end of their final year. They spoke of gaining various types of knowledge and developing interpersonal skills from their placement. Participants also spoke needing to 'fly the nest' and put their learning into practice. From realising they could cope with the workplace their confidence developed further. However in some areas, particularly residential childcare, completing the required documentation took time to learn. A functional level of competence appeared to be expected by employers as reported by Sharpe et al. (2011) and Yu et al. (2016) as participants spoke of working independently, with the same expectations of them as experienced workers.

As students, participants made judgements that they were not ready for some areas of social care based on stories heard from others and their age. Successfully completing placements was associated with judgements of being ready for those areas of practice as also found by Wilson (2013) and Tham and Lynch (2014, 2017). Age was viewed very subjectively in relation to readiness for different areas of social care. Experience working in different areas of social care practice led to judgements about clients and settings that were easier and difficult to work with and in. For some participants working with clients that were motivated and engaged with the service, fitted more with social care values of empowering and improving the quality of life of clients, and were thus preferred. Emergency and short-term homeless services were judged to be particularly difficult due to the level of conflict and the lack of engagement from clients. Unlike other research (Sharpe et al., 2011), although violence was said to be difficult to deal with, the participants were most disheartened by not being able to engage with and help clients, perhaps as relationship building is considered central to social care work (Howard, 2012), as well as social work (Trevithick, 2014).

As also reported by Baginsky and Manthorpe (2016), participants saw placement as particularly contributing to preparedness as it provided them with the opportunity to learn additional knowledge, practise skills and develop self-knowledge. Most participants said that the expectations of them increased over the three placements. However congruent with the literature (Agllias, 2010; Wilson, 2013), some participants noted that placement could not fully replicate the workplace. Compared to workers,students were protected from potentially dangerous situations, were not obliged to engage in the same amount of record keeping, and did not have to challenge clients or make decisions. Students therefore have different or less interactions with clients than workers. As noted by Sharpe et al. (2011) and Wilson (2013), placements are inherently variable due to their own regulations and the need to protect clients so standardised experiences to build all skills cannot not be guaranteed. However being given responsibility on placement, when support was available, was seen to be the best preparation for work by the participants. 
While in the first interview more than a third of participants referred to how learning from different modules combined to provide an understanding of the nature of the work this reduced to three participants in the second interview. While both factual and theoretical knowledge was mentioned by most participants in the second interview, this mainly referred to specific theories or specific material covered as being useful for their current work. This suggests that as workers the focus is on information that is required for the direct work. Some needed time and encouragement to recall theoretical knowledge and pointed out that they had not thought about theory for some time, suggesting that the use of theory to inform practice is not prioritised in the workplace as also found in other studies (Dustin, 2006; Feeney, 2016; McSweeney, 2017). Indeed one participant feared that she was losing necessary theoretical knowledge due to the culture of the organisation in which she worked. Another spoke of realising the relevance of theoretical knowledge learned in college to her work when she was thinking about the interview. There was also an increasing emphasis on the usefulness of what the participants viewed as the practical modules that provided them with skills that were used in work in the second interview. For some participants what was remembered from college was the "stories" told by educators from their own practice experiences. While illustrating concepts with practical examples is valued by students (Simpson et al., 2010), this suggests a danger that what is remembered is the example not the underpinning theory.

There was greater evidence of 'meta-competencies' (Sussman et al., 2014), in particular critical thinking, by participants during the first interview. Taking this along with the appreciation of a broad body of knowledge being necessary for social care work suggests that these participants had achieved a level of coherency and evaluation in their professional knowledge base (Van Bommel, Boshuizen, \& Kwakman, 2012). However this was not as evident when in the workplace, suggesting perhaps that while the educational programme facilitated the reconstruction of knowledge through reflection on placement experiences (Daley, 2001), this was not available in the workplace perhaps due to situational factors (Billett, 2001) or goals and views of workers (Billett, 2010).

On the other hand, some only realised the relevance of reflection when they were in the workplace, although this was something they did by themselves. However reflection focused on practice only rather than integrating theoretical knowledge with practice (Daley, 2001). One participant referred to her learning as contributing to a particular frame of mind suggesting, in agreement with Bates et al. (2010), that she viewed her professional education as contributing to a way of being rather than just acquiring knowledge. The same participant pointed out the responsibility of employing organisations to continue investing in the learning of employees suggesting appreciation of the need for a learning culture in social care agencies (Nixon \& Murr, 2006).

Based on the knowledge they considered they needed to do their work competently, participants pointed out factual and practical knowledge that they thought should be included in the programme. This indicates that they, like some employers (Sharpe et al., 2011), view the purpose of education as being merely to equip them with skills to do their jobs competently, rather than making them utilise the theoretical bases for practice. However when additional practical courses were provided during the college programme some participants did not avail of these opportunities, later explaining that 
they did not see them relevant at that time. Similarly when the requirements for assignments necessitated researching factual knowledge they focused on just completing the assignment rather than seeing their research as contributing to the knowledge needed for practice, as also found by Wilson and Kelly (2010). As the busyness of the workplace is noted to encourage an approach of 'getting through the day', it is not inconceivable to view the busyness of a degree programme to promote a view from students of 'getting through assignments' (Le Maistre \& Paré, 2004, p. 48). Some realised the breadth of social care work and hence the impossibility of a generic degree programme including everything that could be possibly needed for the workplace, as also pointed out by Healy and Meagher (2007).

\section{Conclusion}

Although the sample size is relatively small and all participants are drawn from one graduating class in one institution, this research provides a valuable insight into the subjectivity of students' views of their readiness and preparedness to practice in social care work. That the sample was a volunteer one and participants knew the researchers are potentially limitations. However findings indicate that participants were comfortable in identifying what they perceived as limitations and gaps in the educational programme when discussing their readiness and preparation for practice. Despite commonalities in experiences, differences are evident in participants' judgements of what was useful in preparing them for practice, both in their final year and when in the workplace. This suggests that their views are not solely influenced by their interaction with educators but personal views or interaction with practitioners. Participants who could speak about how a range of theoretical knowledge was necessary for and informed practice became more specific about the usefulness of particular theories for their current work. Others dismissed theory as not being relevant or used after time in employment or had difficulty recalling it. This perhaps indicates that the agenda of the workplace is leading judgements which could result in a 'mechanistic compliance with workplace practices' (Sargeant, 2000 , p. 648) rather than an appreciation that theory along with critical thinking capacity provides a repertoire from which to select 'explanations and solutions' (Van Bommel, Boshuizen, \& Kwakman, 2012, p. 279). Contrary to the findings of others (Healy \& Meagher, 2007; Sussman et al., 2014) that practitioners value 'meta-competencies' in graduates, this is not evident from what these participants saw as important for work.

By interviewing participants at two points in time, this research allows comparison of the views of the same participants at the end of their college year and again when in the workplace, thereby documenting change in what they see as useful in preparing them for practice. The differences perhaps illustrate the emphasis of the activity systems of college and work (Le Maistre \& Paré, 2004). That the use of theoretical knowledge in practice reduces when social care students graduate and become workers suggests that the transfer of knowledge from one activity system to the others is incomplete. Social care educators cannot have a direct impact on the organisation of social care agencies and despite expectations by employers of educational programmes cannot guarantee the successful transfer of learning. However taking the perspective of Billett (2013, p. 6, 2014) that the transfer of knowledge should be conceptualised as 'a problem of learning, 
not education' provides educators with suggestions of how to adjust how theoretical knowledge in particular is presented to students and assessed.

The language used in the college environment could be adapted. As Domakin (Domakin, 2014, p. 720) notes a common phrase used in social work education is 'applying theory to practice', which, she argues, results in a 'myth that knowledge can be bolted onto practice'. Instead, she and others (Fook et al., 2000; Nixon \& Murr, 2006) advocate that experiences in placement rather than theory should lead students' learning. To help students to actively make 'associations and realising reconciliations' (Billett, 2014, p. 5) between theoretical knowledge and practice experiences, educators could encourage learning conversations and debates between students and lecturers and within groups of students (Evans, Guile, Harris, \& Allan, 2010). This may be important to do in modules that are considered to be more distant from the day-to-day work of the social care practitioner such as sociology and social policy (McSweeney, 2017). Such an approach may make theoretical material easier to understand and integrate (Simpson et al., 2010; Tham \& Lynch, 2014).

As students' placement experiences alone may be an insufficient source to cover all the theoretical knowledge that underpins social care practice, these could be supplemented by 'stories' from practice, as they are viewed by both students and practitioners as a valuable source of learning (Beddoe, 2009; Simpson et al., 2010). Beginning with carefully chosen aspects of practice from a variety of situations to analyse could help overcome the transfer issues of having to decontextualise and re-contextualise knowledge for use in the workplace (Billett, 2013). This approach could also be more motivating for students resulting in a more 'effortful engagement' (Billett, 2014, p. 8). As Billett (2014) argues, 'the development of rich conceptual knowledge' requires willingness from students to engage. By presenting the case or story from practice and facilitating students to analyse it using theoretical knowledge could offset the issue that only the story is remembered. Placing students 'in the role of practitioners', Billett (2016, p. 209) argues, improves their recall of knowledge learned and encourages appropriation rather than mastery (Billett, 2010). Encouraging analysis from a variety of theoretical perspectives could also help students to appreciate that theory is a way of making meaning from practice (Van Bommel, Boshuizen, \& Kwakman, 2012) and conflicting explanations coexist. Inviting practitioners who are confident in their use of theoretical knowledge to speak about their experiences and work with students in their analyses as 'knowledge brokers' could enhance the authenticity of this for students (Evans et al., 2010).

This approach could be reflected in how students are assessed. Assessment should 'press students into intentionally extending' theoretical knowledge to practice situations (Billett, 2016, p. 207) as well as encourage students to see theoretical knowledge as 'cultural tools that allow us to act in the world through giving reasons' that can both inform and appraise work practice (Guile, 2006). This may encourage graduates to use their knowledge to support decision-making (Fook et al., 2000).

In preparation for the possibility that graduates will obtain employment in agencies where deliberation on the theoretical underpinnings of practice is not the norm, this could be discussed with students before they graduate, encouraging them to identify possible barriers to applying their knowledge (Weisweiler, Nikitopoulos, Netzel, \& Frey, 2013) and consider their strategies to overcome these. 


\section{Note}

1. For further information, see QQI Award Standards for Social Care Work (2014) https://www. qqi.ie/Publications/Publications/Social\%20Care\%20Work\%20-\%20Awards\%20Standards.pdf and NFQ Referencing of the Irish National Framework to the European Qualifications Framework for Lifelong Learning (2009) https://www.qqi.ie/Documents/Referencing\% 20Irish\%20NFQ\%20to\%20the\%20European\%20QF\%20for\%20Lifelong\%20Learning.pdf.

\section{Disclosure statement}

No potential conflict of interest was reported by the authors.

\section{ORCID}

Fiona McSweeney (D) http://orcid.org/0000-0002-9329-6896

\section{References}

Agllias, K. (2010). Student to practitioner: A study of preparedness for social work practice. Australian Social Work, 63(3), 345-360.

Baginsky, M., \& Manthorpe, H. (2016). The views and experiences of step up to social work graduates: Two and a half years following qualification. British Journal of Social Work, 46(7), 2016-2032.

Bates, N., Immins, T., Parker, J., Keen, S., Rutter, L., Brown, K., \& Zsigo, S. (2010). 'Baptism of fire': The first year in the life of a newly qualified social worker. Social Work Education, 29(2), $152-170$.

Beddoe, L. (2009). Creating continuous conversation: Social workers and learning organisations. Social Work Education, 28(7), 722-736.

Billett, S. (2001). Knowing in practice: Re-conceptualising vocational expertise. Learning and Instruction, 11, 431-452.

Billett, S. (2010). Constituting the workplace curriculum. Journal of Curriculum Studies, 38(1), 31-48.

Billett, S. (2013). Recasting transfer as a socio-personal process of adaptable learning. Educational Research Review, 8, 5-13.

Billett, S. (2014). Integrating learning experiences across tertiary education and practice experiences: A socio-personal account. Educational Research Review, 12, 1-13.

Billett, S. (2015). Readiness and learning in health care education. The Clinical Teacher, 12, 367-372.

Billett, S. (2016). Beyond competence: An essay on a process approach to organising and enacting vocational education. International Journal of Training Research, 14(3), 197-214.

Bradley, G. (2008). The induction of newly appointed social workers: Some implications for social work education. Social Work Education, 27(4), 349-365.

Buckley, H., Tonmyr, L., Lewig, K., \& Jack, S. (2014). Factors influencing the uptake of research evidence in child welfare: A synthesis of findings from Australia, Canada and Ireland. Child Abuse Review, 23(1), 5-16.

Byrne, C. (2016). Ready or not? Statutory registration, regulation and continuing professional development for social care workers in Ireland. Administration, 64(2), 9-29.

Daley, B. J. (2001). Learning and professional practice: A study of four professions. Adult Education Quarterly, 52(1), 39-54.

Domakin, A. (2014). Are we making the most of learning from practice placement? Social Work Education, 33(6), 718-730.

Dustin, D. (2006). Skills and knowledge needed to practise as a care manager. Journal of Social Work, 6(3), 293-313. 
Evans, K., Guile, D., Harris, J., \& Allan, H. (2010). Putting knowledge to work: A new approach. Nurse Education Today, 30, 245-251.

Feeney, A. (2016). A qualitative exploration of how social care practitioners inform their practice through knowledge. (Unpublished master's dissertation). Trinity College Dublin.

Fook, J., Ryan, M., \& Hawkins, L. (2000). Professional expertise: Practice, theory and education for working in uncertainty. London: Whiting \& Birch.

Forester-Jones, R., \& Hatzidimitriadou, E. (2006). Learning in the real world? Exploring widening participation student views concerning the 'fit' between knowledge learnt and work practices. Assessment and Evaluation in Higher Education, 31(6), 611-624.

Frost, E., Höjer, S., \& Campanini, A. (2013). Readiness for practice: Social work students' perspectives in England, Italy and Sweden. European Journal of Social Work, 16(3), 327-343.

Galvani, S., \& Forrester, D. (2011). How well prepared are newly qualified social workers for working with substance use issues? Findings from a national survey in England. Social Work Education, 30(4), 422-439.

Gordon, J., \& Cooper, B. (2010). Talking knowledge - Practising knowledge: A critical best practice approach to how social workers understand and use knowledge in practice. Practice, 22(4), 245-257.

Grant, S., Sheridan, L., \& Webb, S. A. (2017). Newly qualified social workers' readiness for practice in Scotland. British Journal of Social Work, 47(2), 487-506.

Guest, G., MacQueen, K., \& Namey, E. (2012). Applied thematic analysis. Thousand Oaks, CA: Sage.

Guile, D. (2006). Learning across contexts. Educational Philosophy and Theory, 38(3), 251-268.

Hammersley, M. (2003). Recent radical criticism of interview studies: Any implications for the sociology of education? British Journal of Sociology of Education, 24(1), 119-126.

Healy, K., \& Meagher, G. (2007). Social workers' preparation for child protection: Revisiting the question of specialisation. Australian Social Work, 60(3), 321-335.

Howard, N. (2012). The Ryan Report (2009): A practitioner's perspective on implications for residential child care. Irish Journal of Applied Social Studies, 12, 37-48.

Irish Association of Social Care Educators (2009) Practice placement manual. Retrieved from http://staffweb.itsligo.ie/staff/pshare/iasce/Placement\%20Manual\%2029mar09.pdf

Irish Association of Social Workers (2016). About social work. Retrieved from https://www.iasw.ie/

Jack, G., \& Donnellan, H. (2010). Recognising the person within the developing professional: Tracking the early careers of newly qualified child care social workers in three local authorities in England. Social Work Education, 29(3), 305-318.

Le Maistre, C., \& Paré, A. (2004). Learning in two communities: The challenge for universities and workplaces. Journal of Workplace Learning, 16(1/2), 44-52.

McDonald, C. (2007). "This is who we are and this is what we do": Social work education and self-efficacy. Australian Social Work, 60(1), 83-93.

McLeod, J. (2001). Qualitative research in counselling and psychotherapy. London, England: Sage Publications.

McPheat, G., \& Butler, L. (2014). Residential care agencies as learning organisations: Innovation and learning from mistakes. Social Work Education, 33(2), 240-253.

McSweeney, F. (2017). Learning for work: Social identities and professional education in social care. Saarbrucken: VDM Verlag Dr. Muller.

McSweeney, F. (2017). Supervision of students in social care education: Practice teachers' views of their role. Social Work Education, 36(1), 36-47.

McSweeney, F., Smith, K., \& Williams, D. (2016). Introduction: Reflections on the provision, organisation and management of social care in Ireland. Administration, 64(2), 1-6.

McSweeney, F., \& Williams, D. (2018). Social care students' learning on the practice placement in Ireland. Social Work Education, 37(5), 581-596.

Newberry, A. (2014). Hitting the ground running: Neo-conservatism and first-year Canadian social workers. Critical Social Work, 15(1), 42-55.

Nixon, S., \& Murr, A. (2006). Practice learning and the development of professional practice. Social Work Education, 25(8), 798-811. 
Pithouse, A., \& Scourfield, J. (2002). Ready for practice? The DipSW in Wales. Journal of Social Work, 2(1), 7-27.

Pösö, T., \& Forsman, S. (2013). Messages to social work education: What makes social workers continue to cope in child welfare? Social Work Education, 32(5), 650-661.

Rapley, T. J. (2001). The art(fullness) of open-ended interviewing: Some considerations on analysing interviews. Qualitative Research, 1(3), 303-323.

Redmond, B., Guerin, S., \& Devitt, C. (2008). Attitudes, perceptions and concerns of student social workers: First two years of a longitudinal study. Social Work Education, 27(8), $868-882$.

Sandars, J. (2005). An activity theory perspective. Work Based Learning in Primary Care, 3, 191-201.

Sargeant, A. V. (2000). An exploratory study of the effects of progression towards national vocational qualifications on the occupational knowledge and care practice of social care workers. Social Work Education, 19(6), 639-661.

Sharpe, E., Moriarty, J., Stevens, M., Manthorpe, J., \& Hussein, S. (2011). Into the workforce: Report on a study of new social work graduates. London: Sharpe Research; Social Care Workforce Research Unit; King's College London.

Simpson, D., Mathews, I., Croft, A., McKinna, G., \& Lee, M. (2010). Student views on good practice in social work education. Social Work Education, 29(7), 729-743.

Smith, M. (2005). Applying ideas from learning and teaching in higher education to develop professional identity: The case of the MSc in advanced child care. Child and Youth Care Forum, 34(4), 261-277.

Social Care Ireland (2016). What is social care work? Retrieved from https://www.socialcareireland.ie

Sussman, T., Bailey, S., Byford Richardson, K., \& Granner, F. (2014). How field instructors judge BSW student readiness for entry-level practice. Journal of Social Work Education, 50(1), 84-100.

Tham, P., \& Lynch, D. (2014). Prepared for practice? Graduating social work students' reflections on their education competence and skills. Social Work Education, 33(6), 704-717.

Tham, P., \& Lynch, D. (2017). 'Lost in transition?' - Newly educated social workers' reflections on their first months in practice. European Journal of Social Work. doi:10.1080/ 13691457.2017.1364701

Trevithick, P. (2008). Revisiting the knowledge base of social work: A framework for practice. British Journal of Social Work, 38(6), 1212-1237.

Trevithick, P. (2014). Humanising managerialism: Reclaiming emotional reasoning, intuition, the relationship and knowledge and skills in social work. Journal of Social Work Practice, 28(3), 287-311.

Van Bommel, M., Boshuizen, H. P. A., \& Kwakman, K. (2012). Appraising the qualities of social work students' theoretical knowledge: A qualitative exploration. Vocations and Learning, 5(3), 277-295.

Van Bommel, M., Kwakman, K., \& Boshuizen, H. P. A. (2012). Experiences of social work students with learning theoretical knowledge in constructivist higher vocational education: A qualitative exploration. Journal of Vocational Education and Training, 64(4), 529-542.

Weisweiler, S., Nikitopoulos, A., Netzel, J., \& Frey, D. (2013). Gaining insight to transfer of training through the lens of social psychology. Educational Research Review, 8, 14-27.

Wilson, G. (2013). Preparing social workers for practice: Re-evaluating student learning needs. Social Work Education, 32(5), 590-606.

Wilson, G. (2014). Building partnerships in social work education: Towards achieving collaborative advantage for employers and universities. Journal of Social Work, 14(1), 3-22.

Wilson, G., \& Kelly, B. (2010). Evaluating the effectiveness of social work education: Preparing students for practice learning. British Journal of Social Work, 40(8), 2431-2449.

Yu, N., Moulding, N., Buchanan, F., \& Hand, T. (2016). How good is good enough? Exploring workers' conceptions of preparedness for practice. Social Work Education, 35(4), 414-429. 